\title{
Postaxial polydactyly-anterior pituitary anomalies-facial dysmorphism syndrome
}

INSERM

\section{Source}

INSERM. (1999). Orphanet: an online rare disease and orphan drug data base. Postaxial polydactyly-anterior pituitary anomalies-facial dysmorphism syndrome. ORPHA:420584

Postaxial polydactyly-anterior pituitary anomalies-facial dysmorphism syndrome is a rare, genetic developmental defect during embryogenesis disorder characterized primarily by congenital hypopituitarism and/or postaxial polydactyly. It can be associated with short stature, delayed bone age, hypogonadotropic hypogonadism, and/or midline facial defects (e.g. hypotelorism, mild midface hypoplasia, flat nasal bridge, and cleft lip and/or palate). Hypoplastic anterior pituitary and ectopic posterior pituitary lobe are frequent findings on MRI examination. 